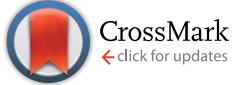

Cite this: RSC Adv., 2017, 7, 13742
Received 5th November 2016 Accepted 23rd February 2017

DOI: $10.1039 / \mathrm{c} 6 \mathrm{ra} 26341 \mathrm{k}$

rsc.li/rsc-advances

\section{Electrochemical impedance spectroscopy (EIS) study on the degradation of acrylic polyurethane coatings}

\author{
Fuyou Lu, ${ }^{\text {abcd }}$ Baodong Song, ${ }^{\text {*a }}$ Pei He, ${ }^{\text {abcd }}$ Zhi Wang ${ }^{\text {abcd }}$ and Jixiao Wang *abcd
}

Two component polyurethane coatings are widely used for materials protection. Herein, a series of acrylic polyurethane coatings were prepared by reaction of hydroxyl acrylic resin and hexamethylene diisocyanate (HDI) biuret. These coatings have different isocyanate to hydroxyl ratios (expressed as $\mathrm{NCO} / \mathrm{OH}$ ). The degradation process of the coatings was evaluated by electrochemical impedance spectroscopy measurement. Then, the results were analyzed using equivalent electrical circuits. Besides, the adhesion and water resistance of the coatings were also investigated. Experimental results demonstrated that the higher the $\mathrm{NCO} / \mathrm{OH}$ ratios within a certain range, the better the corrosion resistance. Specifically, the coating with $\mathrm{NCO} / \mathrm{OH}=1.4$ provided the best corrosion resistance, and its impedance modulus still remained at close to $1 \times 10^{11}$ ohms per $\mathrm{cm}^{2}$ after 50 days immersion. However, the corrosion resistance of coatings with $\mathrm{NCO} / \mathrm{OH}=0.8$ and $\mathrm{NCO} / \mathrm{OH}=1.0$ were relatively poor. More interestingly, with the increase in $\mathrm{NCO} / \mathrm{OH}$ ratios, the coating's adhesion increased slightly and the water resistance improved noticeably.

\section{Introduction}

Organic coatings play a very important role in the protection of materials. Polyurethane coatings have the characteristics of good abrasion resistance and high flexibility, and good physical and mechanical properties. They are widely used in the automotive, furniture and ship surface fields. ${ }^{1-5}$ It is generally considered that polyurethane is a block copolymer composed of a soft segment and a hard segment. The soft segment pertains to various polyols or ammonia (terminal hydroxyl or amine groups polymer), such as polyester polyol, polyether polyol and acrylic polyol or mixtures of them. The hard segment includes chain extenders and curing agents. ${ }^{6,7}$ In particular, the coatings prepared by hydroxyl acrylic resin and aliphatic isocyanate exhibit a better performance, and are widely used in high performance establishments. ${ }^{\mathbf{8} 9}$ Nevertheless, isocyanate curing agents usually react with water from moisture, water in pigments or amines of pretreated pigments, ${ }^{\mathbf{1 0}}$ resulting in coatings that have cured thoroughly possessing different NCO/ $\mathrm{OH}$ ratios. Further, different $\mathrm{NCO} / \mathrm{OH}$ ratios affect corrosion

${ }^{a}$ CERC, School of Chemical Engineering and Technology, Tianjin University, Tianjin 300072, PR China. E-mail: bdsong@tju.edu.cn; jxwang@tju.edu.cn; Fax: +86 22 27404757; +8622 27404496; Tel: +8622 27403584; +8622 27404533

${ }^{b}$ Tianjin Key Laboratory of Membrane Science and Desalination Technology, Tianjin University, Tianjin 300072, PR China

${ }^{c}$ State Key Laboratory of Chemical Engineering, Tianjin University, Tianjin 300072, PR China

${ }^{d}$ Collaborative Innovation Center of Chemical Science and Engineering (Tianjin), Tianjin University, Tianjin 300072, PR China resistance, water absorption, and adhesion properties of coatings significantly. ${ }^{11-13}$ But above all, it is difficult to get detailed impact information on the $\mathrm{NCO} / \mathrm{OH}$ ratios of the coatings from coating distributors and manufacturers. Thus, it is necessary to investigate the effect of $\mathrm{NCO} / \mathrm{OH}$ ratios on the comprehensive performance of acrylic polyurethane coatings.

We study the degradation behavior of acrylic polyurethane varnish with different $\mathrm{NCO} / \mathrm{OH}$ ratios in saline solution. The coated specimens were immersed in $3.5 \mathrm{wt} \% \mathrm{NaCl}$ solution at $50{ }^{\circ} \mathrm{C}$ for 50 days. Then, electrochemical impedance spectroscopy (EIS) was conducted. By the way, EIS was an effective tool for examination and evaluation of the protective properties of organic coatings. ${ }^{\mathbf{1 4 , 1 5}}$ Furthermore, it is rapid and has no destructive effective on samples. ${ }^{16,17}$ Finally, results of the EIS measurement were simulated and analyzed by equivalent electrical circuits (EEC) deep. Besides, the effects of $\mathrm{NCO} / \mathrm{OH}$ ratios on adhesion and water resistance of the coatings were also investigated roundly. These research results would provide important information to product excellent two component acrylic polyurethane coatings.

\section{Experimental section}

\subsection{Materials}

Hydroxyl acrylic resin $(1107 \mathrm{~N}$, hydroxyl groups content is 3.2 wt\%) was purchased from Foshan gaoming tod chemical Ltd. Co., China. The HDI biuret (N75, NCO groups content is 16.8 wt\%) was obtained from Bayer Co., Germany. Organic Tin Catalyst (DBTDL-T12) was purchased from Shanghai Aladdin 
Bio-Chem Technology Ltd., China. Butyl acetate (BAC) supplied as thinner was purchased from Tianjin Jiangtian Reagent Ltd. Co., China. All chemical materials are analytical reagent and used directly without further purification. No pigments and other fillers were added to the coatings.

Mild steel plates, $80 \mathrm{~mm} \times 30 \mathrm{~mm} \times 3 \mathrm{~mm}$ (Q235, C: $0.17-$ $0.24 \%$; Si: $0.17-0.37 \%$; Mn: $0.35-0.65 \%$; S: $<0.030 \%$; P: $<0.030 \%$ ), were used as the metal substrates. The steel plates were grinded with $360 \#$, 600\#, 1000\# and 1500\# abrasive papers to remove the rust, followed by a thorough rinse with anhydrous ethanol and acetone. Polycarbonate sheets are used as substrates for obtaining detached coating sheets.

\subsection{Preparation of coatings}

Firstly, stoichiometric hydroxyl acrylic resin, BAC and DBTDL were mixed and ultrasonicated for dispersion. Then, the N75 was added into the above mixtures using an ultrasonic homogenizer for another five minutes to form homogeneous coatings. Coatings with different ratios of $\mathrm{NCO} / \mathrm{OH}$ (that is 0.8 , 1.0, 1.2 and 1.4) were prepared by adjusting the amount of N75. Finally, the formed coatings were brushed onto the pretreated steel plates. To avoid pinhole defects, the specimens was brushed twice. All the coated samples were cured at ambient temperature for 24 hours and then at $60{ }^{\circ} \mathrm{C}$ for 12 hours. The dried thickness of the coatings is about $60 \pm 10 \mu \mathrm{m}$. Curing mechanism of the coatings is shown below Scheme 1 .

\subsection{Characterizations}

The electrochemical workstation (VersaSTAT, USA) was employed with a three-electrode arrangement cell with $3.5 \mathrm{wt} \%$ $\mathrm{NaCl}$ as the electrolyte. Graphite electrode, saturated calomel electrode (SCE) and coated specimen were used as counter electrode, reference electrode and working electrode respectively. The valid area of the working electrode was $1.00 \mathrm{~cm}^{2}$. EIS measurements were conducted after different immersion intervals in $3.5 \mathrm{wt} \% \mathrm{NaCl}$ solution. The measurements frequencies ranges from $0.01 \mathrm{~Hz}$ to $100 \mathrm{kHz}$ with a $10 \mathrm{mV}$ amplitude. All measurements were carried out in a faraday cage to avoid Coulombs fields. ${ }^{18}$ The impedance data were fitted and analyzed with equivalent electrical circuit models by ZsimpWin software.

The morphology of the coating surface was observed before and after immersion by scanning electron microscopy (SEM) with a JEOL JSM-6700F microscope. The optical photographs of specimens after immersion for 50 days were also recorded by a HD camera.

Contact angle (CA) of the coatings was measured to evaluate the hydrophilicity and hydrophobicity by a Dataphysics OCA15EC contact-angle goniometer. Water absorption process of the coatings was test as well by gravimetric method. Detailedly, dry samples $(30.0 \mathrm{~mm} \times 80.0 \mathrm{~mm})$ were weighed and then immersed in distilled water. The coating films were immersed in deionized water for some time and then taken out from the water, then absorbing the visible water droplets on surface of samples quickly with a homemade apparatus as shown in Scheme 2.

Because of the high aspect ratio of coating films, the edge of the coating is no need to be sealed with wax. The filtration paper is need to be renew for every sample, at least three parallel samples were used to test. The samples were weighed regularly until the weight reaching a stable value. The water absorption ratio $(W \%)$ was determined by the following equation: ${ }^{19}$

$$
W(\%)=\frac{M_{t}-M_{0}}{M_{0}} \times 100 \%
$$

where $W$ is the water absorption ratio, $M_{0}$ is the weight of dry coating film, and $M_{t}$ is the weight after immersion time $t$.

Chemical proportion differences of the coatings were monitored by FTIR-ATR analysis using a Bio-Rad FTS 6000 spectrometer. The ATR attachment was used with 16 scans and a resolution of $8 \mathrm{~cm}^{-1}$ during the range of $4000-650 \mathrm{~cm}^{-1}$.

Adhesion measurements of the coatings on steel plates were tested by pulling off dollies stuck vertically on the surface with a PosiTest Adhesion Tester (PosiTest AT-M, Defelsko, USA).

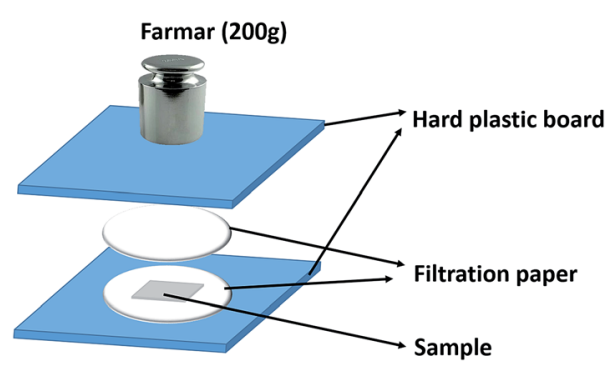

Scheme 2 A homemade apparatus for removing residual water droplets under the identical condition.

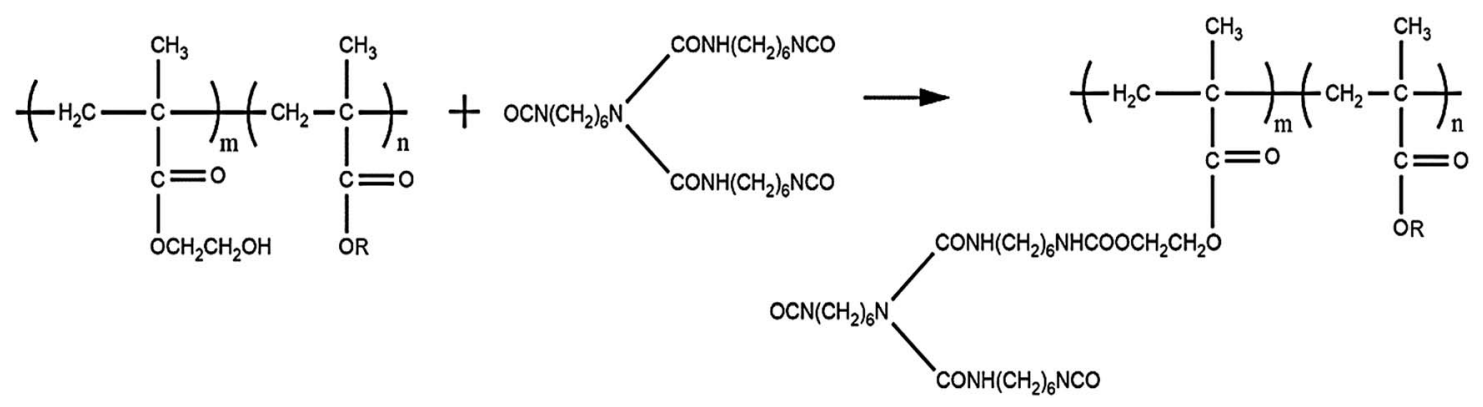

Scheme 1 The reaction of acrylic resin and hexamethylene diisocyanate (HDI) biuret. 
There were five dollies on each sample. All the measurements were conducted at room temperature.

\section{Result and discussion}

As is known, corrosion of metals include complex electrochemical reactions. It is applicable to analyze the degradation process of coatings by electrochemical measurements. ${ }^{\mathbf{2 0 2}}$ The Bode and Nyquist plots of different samples are shown below. We can conclude from Fig. 1 that, impedance spectra changes of the samples at different time are obviously. In order to clearly present the capacitive loops at low frequencies, the Nyquist plots at low frequencies are magnified.

Fig. 1 and 2 are the Bode and Nyquist plots respectively. Initially, all samples show a very high resistance $\left(>10^{10} \mathrm{ohms}\right.$ per $\mathrm{cm}^{2}$ ) at low frequencies. The Bode plots are close to a straight line with a slope of -1 and the Nyquist plots is close to the $Y$ axis. The phenomena indicated that the coatings act as a pure capacitor at initial days of immersion. ${ }^{22}$ Then the impedance at the low frequencies gradually decreased with increasing of immersion time. The Nyquist graph slope of the coating with $\mathrm{NCO} / \mathrm{OH}=0.8$ changed from the $Y$ axis to the $X$ axis obviously. And after immersion for 11 days, an obvious trailing semicircle corresponding to two time constants appeared. This phenomenon means the dramatically decrease of coating protection property and the initial corrosion at the metal/coating interface. However, after immersion for 11 days, coating with $\mathrm{NCO} / \mathrm{OH}=1.0,1.2$ and 1.4 showed no obvious semicircle corresponding to only one time constants. Ordinarily, time constants refers to barrier performance of organic coatings, ${ }^{23}$ therefore, the last three samples had no obvious corrosion.

After 50 days of immersion, the coating with $\mathrm{NCO} / \mathrm{OH}=1.4$ still maintained very high impedance and the modulus was as high as $10^{11} \mathrm{ohms}$ per $\mathrm{cm}^{2}$ at low frequencies. For the coating with $\mathrm{NCO} / \mathrm{OH}=1.2$, the impedance modulus at $0.01 \mathrm{~Hz}$ is greater than $10^{9}$ ohms per $\mathrm{cm}^{2}$. As we known, higher than $10^{7}$ ohms per $\mathrm{cm}^{2}$ impedance at low frequencies means excellent protection for substrate of the coatings. ${ }^{24,25}$ While, the impedance modulus of both coatings with $\mathrm{NCO} / \mathrm{OH}=0.8$ and coatings with $\mathrm{NCO} / \mathrm{OH}=1.0$ at $0.01 \mathrm{~Hz}$ decreased to nearly $1 \times 10^{6}$ ohms per $\mathrm{cm}^{2}$, which indicated the coatings almost losing its protection ability for substrates. It was also found that the Nyquist plots of both coatings of $\mathrm{NCO} / \mathrm{OH}=0.8$ and 1.0 possessed two incomplete capacitive loops after 50 days of immersion. The half circle at high frequency was attributed to the coating protection performance, and the half circle at low frequency was related to the products underneath the coating. ${ }^{26-28}$ This phenomenon indicated there have generated a serious corrosion. Besides, the Nyquist plot of coating with $\mathrm{NCO} / \mathrm{OH}=1.4$ also showed two unsharp incomplete capacitive loops. It mean the charge transfer resistance is just forming, (a)

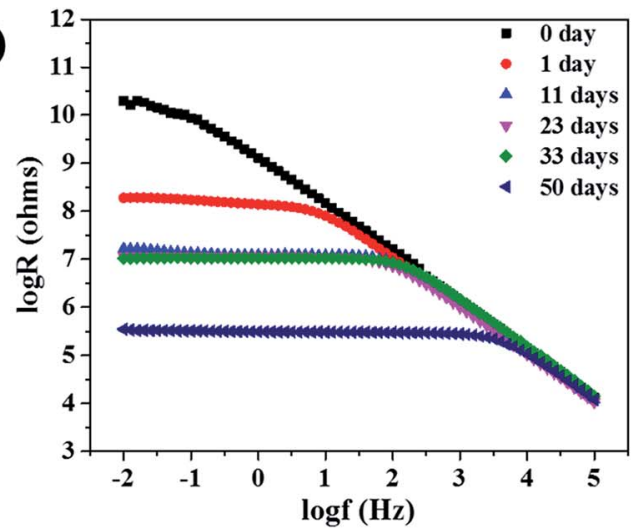

(c)

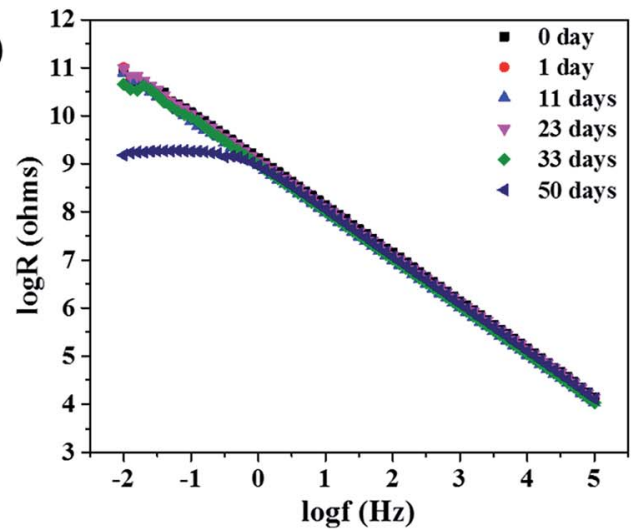

(b)

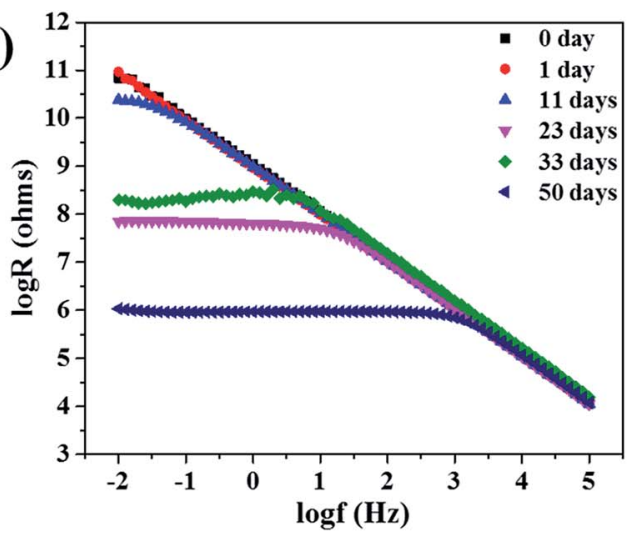

(d)

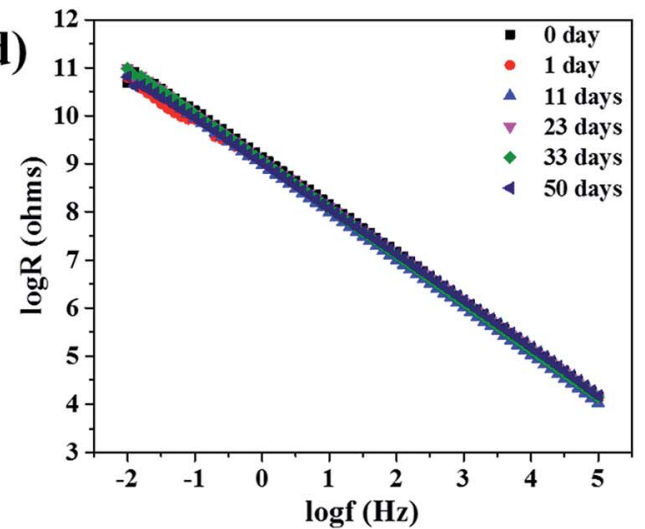

Fig. 1 Bode plots of samples in $3.5 \mathrm{wt} \% \mathrm{NaCl}$ solution after different immersion times: (a) the coating with $\mathrm{NCO} / \mathrm{OH}=0.8$; (b) the coating with $\mathrm{NCO} / \mathrm{OH}=1.0$; (c) the coating with $\mathrm{NCO} / \mathrm{OH}=1.2$; (d) the coating with $\mathrm{NCO} / \mathrm{OH}=1.4$. 

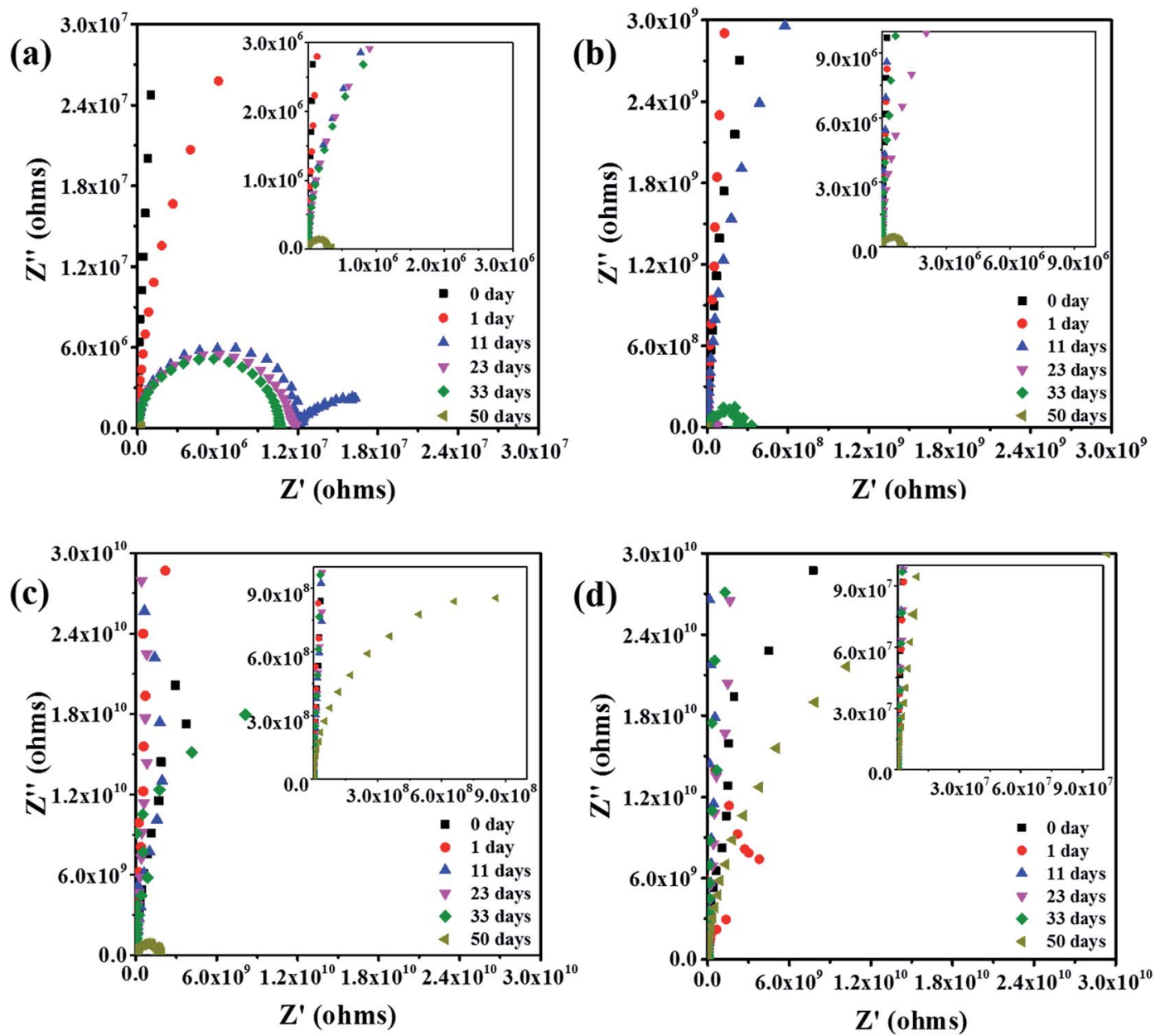

Fig. 2 Nyquist plots of specimens in $3.5 \mathrm{wt} \% \mathrm{NaCl}$ solution after different immersion times: (a) the coating with $\mathrm{NCO} / \mathrm{OH}=0.8$; (b) the coating with $\mathrm{NCO} / \mathrm{OH}=1.0$; (c) the coating with $\mathrm{NCO} / \mathrm{OH}=1.2$; (d) the coating with $\mathrm{NCO} / \mathrm{OH}=1.4$.

which may attribute to slight delamination on the interface between metal and coating. Consequently, the barrier effect of the coatings with higher $\mathrm{NCO} / \mathrm{OH}$ ratios were better.

Equivalent electrical circuits (EEC) were used to quantitatively analyze the degradation degree of coatings. The EEC of the sample with $\mathrm{NCO} / \mathrm{OH}=0.8$ after immersion for 50 days was showed in Fig. 3(a). We can see that, the coatings lost the barrier property completely and formed a new diffusion layer consist of the corrosion products. However, the coatings with $\mathrm{NCO} / \mathrm{OH}=$ 1.4 still had high protective performance after immersion for 50 days as shown in Fig. 3(b). The charge transfer was the control step of corrosion process. These two classical EEC contained (a)

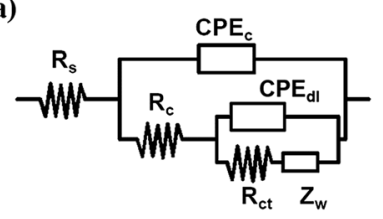

(b)

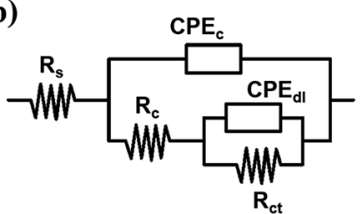

Fig. 3 EEC models selected to fit the EIS measurement: (a) the coating with $\mathrm{NCO} / \mathrm{OH}=0.8$; (b) the coating with $\mathrm{NCO} / \mathrm{OH}=1.4$. solution resistance $\left(R_{\mathrm{s}}\right)$, coating resistance $\left(R_{\mathrm{c}}\right)$, coating capacitance $\left(\mathrm{CPE}_{\mathrm{c}}\right)$, double layer capacitance $\left(\mathrm{CPE}_{\mathrm{dl}}\right)$ and charge transfer resistance $\left(R_{\mathrm{ct}}\right) . Z_{\mathrm{w}}$ representing the Warburg impedance, which resulted from the diffusion of ions from the electrolyte to the electrode interface. Constant phase elements (CPE) are employed to replace capacitance $(C)$ elements with dispersion effect to obtain more precious fitting results..$^{29,30}$

The fitting results of both Bode plots and phase angle plots after 50 days immersion were shown in Fig. 4 . And the simulated parameters of electrochemical elements were listed in Table 1. The experimental results matched well with the calculated results of equivalent electrical circuits. After immersion for 50 days, the coating resistance $\left(R_{\mathrm{c}}\right)$ increased obviously with the increase of the $\mathrm{NCO} / \mathrm{OH}$ ratios. Specifically, the resistance of the coating with $\mathrm{NCO} / \mathrm{OH}=1.4$ was $1.19 \times 10^{8}$, reflecting the coating could prevent electrolyte penetrating into the coatings effectively. While, the resistance of the coating with $\mathrm{NCO} / \mathrm{OH}=0.8$ was very low, with a value of $2.93 \times 10^{5}$. In order to compare the difference between capacitance $\left(C_{\mathrm{c}}\right)$ and double layer capacitance $\left(C_{\mathrm{dl}}\right), C_{\mathrm{c}}$ values and $\mathrm{CPE}_{\mathrm{dl}}$ values according to the fitting $\mathrm{CPE}_{\mathrm{c}}$ and $\mathrm{CPE}_{\mathrm{dl}}$ values respectively were calculated purposely. The calculation results showed that the $C_{\mathrm{c}}$ were of 

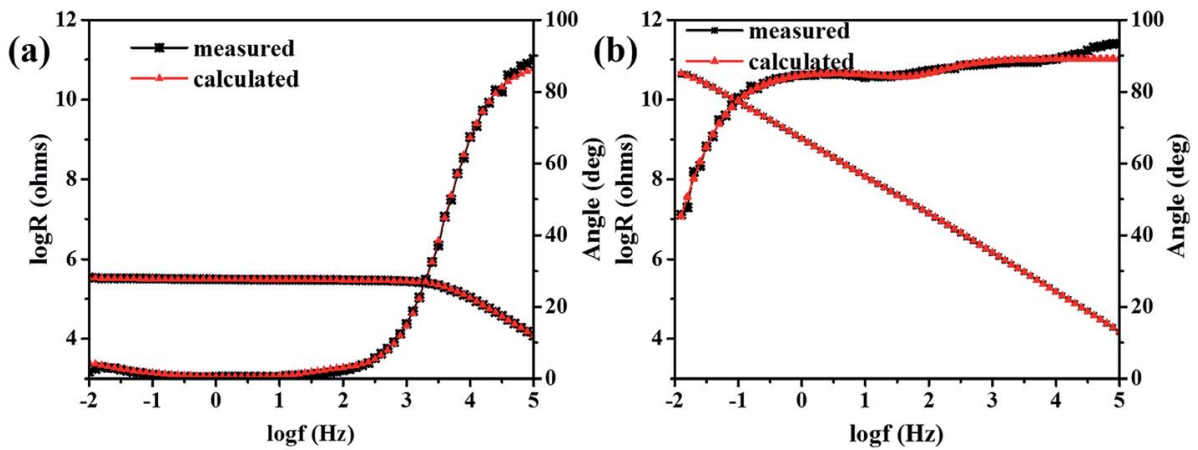

Fig. 4 The EEC fitting results of (a) the coating with $\mathrm{NCO} / \mathrm{OH}=0.8$ and (b) the coating with $\mathrm{NCO} / \mathrm{OH}=1.4$ after 50 days immersion

Table 1 The simulated parameters of electrochemical elements after 50 days immersion

\begin{tabular}{|c|c|c|c|c|c|c|}
\hline $\mathrm{NCO} / \mathrm{OH}(\mathrm{R})$ & $R_{\mathrm{S}}\left(\mathrm{ohms}\right.$ per $\left.\mathrm{cm}^{2}\right)$ & $R_{\mathrm{c}}\left(\mathrm{ohms}\right.$ per $\left.\mathrm{cm}^{2}\right)$ & $C_{\mathrm{c}}\left(\mathrm{F} \mathrm{cm}^{-2}\right)$ & $R_{\mathrm{ct}}\left(\mathrm{ohms}\right.$ per $\left.\mathrm{cm}^{2}\right)$ & $C_{\mathrm{dl}}\left(\mathrm{F} \mathrm{cm}^{-2}\right)$ & $Z_{\mathrm{w}}\left(\right.$ ohms per $\left.\mathrm{cm}^{2}\right)$ \\
\hline 0.8 & $1.00 \times 10^{-2}$ & $2.93 \times 10^{5}$ & $1.40 \times 10^{-10}$ & $1.67 \times 10^{4}$ & $1.41 \times 10^{-7}$ & $2.6 \times 10^{-6}$ \\
\hline 1.0 & $1.62 \times 10^{-2}$ & $8.19 \times 10^{5}$ & $1.33 \times 10^{-10}$ & $1.14 \times 10^{5}$ & $9.74 \times 10^{-10}$ & \\
\hline 1.4 & $1.01 \times 10^{-2}$ & $1.19 \times 10^{8}$ & $1.20 \times 10^{-10}$ & $7.30 \times 10^{10}$ & $8.31 \times 10^{-11}$ & \\
\hline
\end{tabular}
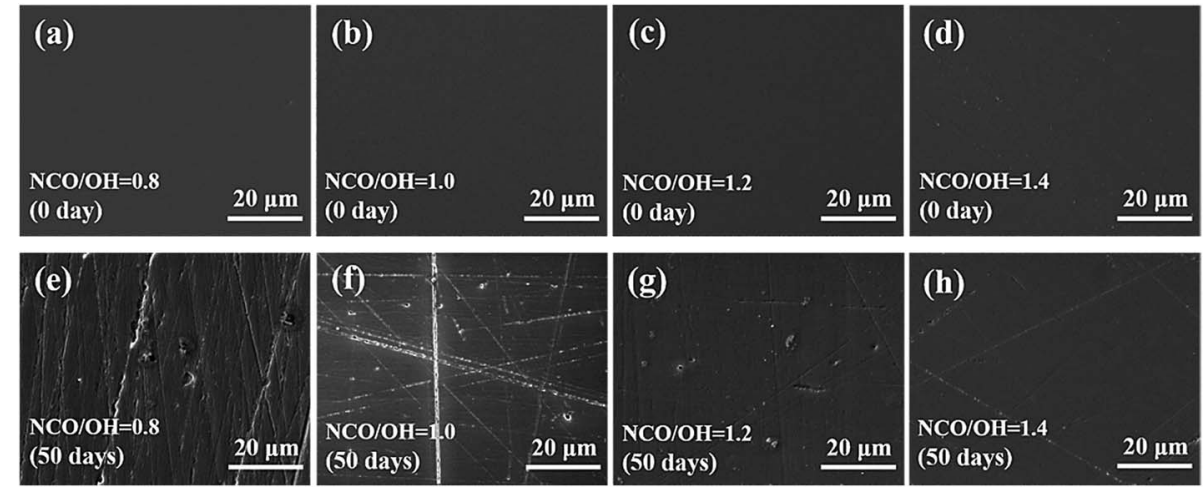

Fig. 5 SEM images of surface of the coating with (a) $\mathrm{NCO} / \mathrm{OH}=0.8$ before immersion; (b) $\mathrm{NCO} / \mathrm{OH}=1.0$ before immersion; (c) $\mathrm{NCO} / \mathrm{OH}=1.2$ before immersion; (d) $\mathrm{NCO} / \mathrm{OH}=1.4$ before immersion; (e) $\mathrm{NCO} / \mathrm{OH}=0.8$ for 50 days immersion; (f) $\mathrm{NCO} / \mathrm{OH}=1.0$ for 50 days immersion; (g) $\mathrm{NCO} / \mathrm{OH}=1.2$ for 50 days immersion and $(\mathrm{h}) \mathrm{NCO} / \mathrm{OH}=1.4$ for 50 days immersion.

the same order of magnitude at different $\mathrm{NCO} / \mathrm{OH}$ ratios. Precisely, $C_{\mathrm{c}}$ decreased with the increase of the $\mathrm{NCO} / \mathrm{OH}$ ratios, which was caused by different water content of the coatings. It is generally considered that, the higher the value of $C_{\mathrm{dl}}$ is, the more serious delamination. ${ }^{31}$ As you can see, the $C_{\mathrm{dl}}$ decreased obviously with the increase of $\mathrm{NCO} / \mathrm{OH}$, which was attributed to massive polar effect of excess NCO. $R_{\mathrm{ct}}$ is supposed to reflect the trend of electrochemical reactions, and the smaller the value of $R_{\mathrm{ct}}$, the more difficult the protection. ${ }^{32}$ We can see from Table 1 that, $R_{\mathrm{ct}}$ increased with the increase of the $\mathrm{NCO} / \mathrm{OH}$ ratios. That is to say, coatings with high ratios of $\mathrm{NCO} / \mathrm{OH}$ were not easy to degrade, which was coincide with Bode and Nyquist results.

Morphologies of the surface of the coatings are shown in Fig. 5. The figures clearly showed that there was no difference between coatings with different $\mathrm{NCO} / \mathrm{OH}$ ratios before immersion. While, after 50 days immersion, many scratches appeared on the coating with $\mathrm{NCO} / \mathrm{OH}=0.8$ and $\mathrm{NCO} / \mathrm{OH}=1.0$, destruction and decomposition occurred. On the contrary, the coating with $\mathrm{NCO} / \mathrm{OH}=1.4$ appeared a few scratches, and there was no obvious degradation. As showed in Fig. 6, the coatings with lower $\mathrm{NCO} / \mathrm{OH}$ ratios corroded seriously. The coating with $\mathrm{NCO}=1.4$ just appeared little delamination after 50 days
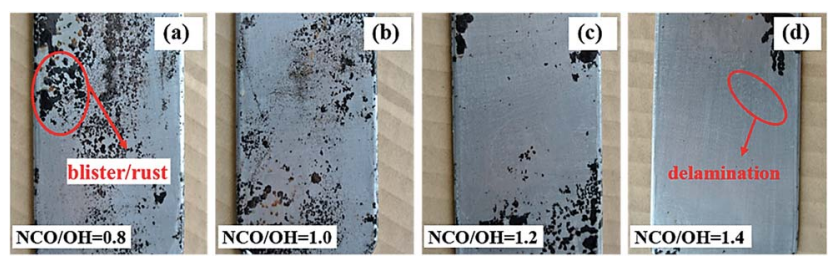

Fig. 6 Photographs of specimens exposed in $3.5 \mathrm{wt} \% \mathrm{NaCl}$ solution at $50{ }^{\circ} \mathrm{C}$ after 50 days. 
immersion. It was consistent with the above impedance characterization results.

Water absorption of coatings was characterized by gravimetric method. As shown in Fig. 7, the water absorption of all the coatings was less than $0.45 \mathrm{wt} \%$, and decreased with

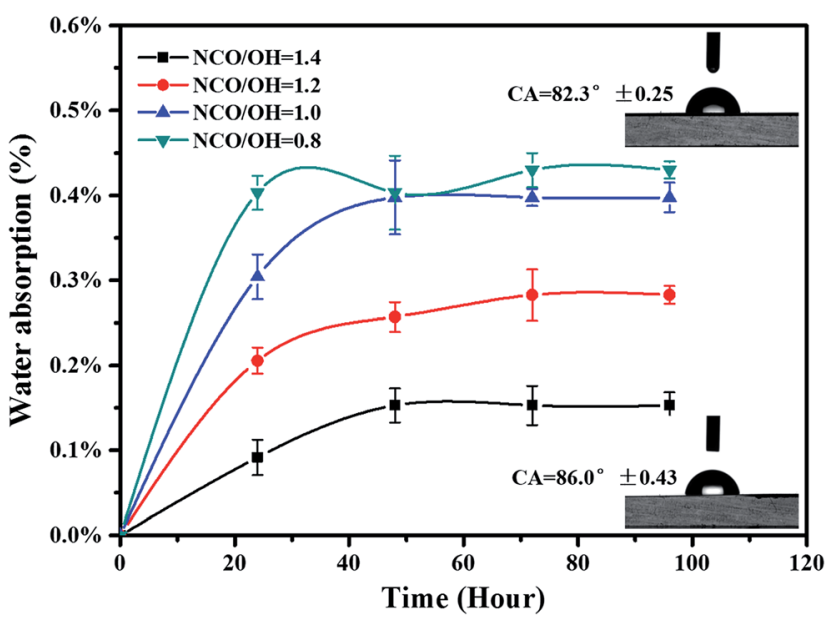

Fig. 7 Water absorption rate and wettability of coatings.

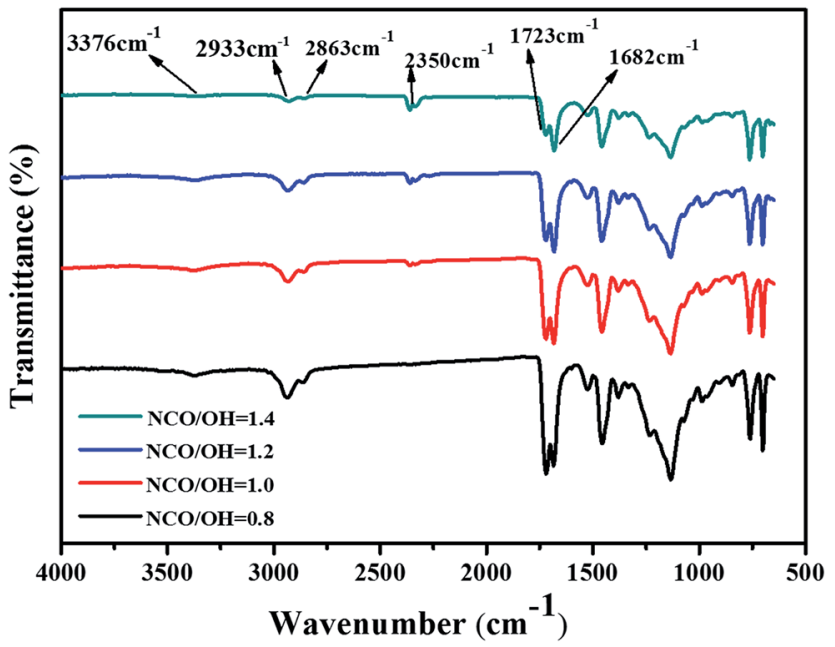

Fig. 8 ATR-FTIR spectra of different $\mathrm{NCO} / \mathrm{OH}$ ratios acrylic polyurethane coating in the range $650-4000 \mathrm{~cm}^{-1}$. increase of the $\mathrm{NCO} / \mathrm{OH}$ ratios. The water absorption is only $0.15 \%$ wt $\%$ when the $\mathrm{NCO} / \mathrm{OH}$ value was 1.4 , which showed the coating film has good water resistance. However, when the $\mathrm{NCO} / \mathrm{OH}$ ratio was lower than the stoichiometric ratio, polymers had excrescent hydroxyl groups. Thus, water molecules permeated into the coatings more easily. Wettability of coatings was also characterized auxiliarily by contact angle measurement. It was found that the static contact angles of the coating with $\mathrm{NCO} / \mathrm{OH}=0.8$ and $\mathrm{NCO} / \mathrm{OH}=1.4$ were $82.3^{\circ}$ and $86.0^{\circ}$ respectively. The former possessed better hydrophilicity, because the more the content of hydroxyl acrylic resin, the better hydrophilic of the coatings.

FTIR-ATR was also used to analyze the structure of the coatings (as showed in Fig. 8). There is a very weak wide peak at $3506 \mathrm{~cm}^{-1}$, it represents the absorption peak of $\mathrm{O}-\mathrm{H}$. The peak at $3376 \mathrm{~cm}^{-1}$ represents the stretching vibration absorption of $\mathrm{N}-\mathrm{H}$. The peaks at $2863 \mathrm{~cm}^{-1}$ and $2933 \mathrm{~cm}^{-1}$ are attributed to the stretching vibration absorption of $\mathrm{C}-\mathrm{H}$. Especially, the peak at 2350 attributed to the stretching vibration absorption of -NCO, explaining unreacted NCO groups in coatings with NCO/ $\mathrm{OH}=1.2$ or 1.4 . In general, hydrogen bonded carbonyl groups appear at low frequency range compared with free carbonyl band. ${ }^{3,34}$ The peak at $1682 \mathrm{~cm}^{-1}$ and the peak at $1723 \mathrm{~cm}^{-1}$ are attributed to the hydrogen bonded carbonyl group $(\mathrm{C}=\mathrm{O})$ and the stretching vibration absorption of free carbonyl group $(\mathrm{C}=$ $\mathrm{O})$ respectively. Results show that there are a few unreacted NCO groups on the coating with $\mathrm{NCO} / \mathrm{OH}=1.4$, and there are several unreacted $\mathrm{OH}$ groups on the coating with $\mathrm{NCO} / \mathrm{OH}=0.8$. These results explain the difference of water resistance and corrosion resistance of coating with varied $\mathrm{NCO} / \mathrm{OH}$ ratios.

Adhesion measurements were also performed, and each sample was measured at five points. The average values were plotted in Fig. 9(a). It can be seen from the figure that, the adhesion strength of the coating slightly improved with the increase of $\mathrm{NCO} / \mathrm{OH}$ ratios. However, it was found that range of the error bars was very large. In order to further illustrate this phenomenon, the pictures of adhesion test were placed in Fig. 9(b). Generally, when all paint film is pulled off, the adhesion strength of the coatings is accurate. But, under certain conditions, there were some adhesives cracked internally and dollies not pulled off from the specimen, because the adhesion strength was beyond the using upper limit of the adhesive or machine. These phenomena indicated that the actual adhesion

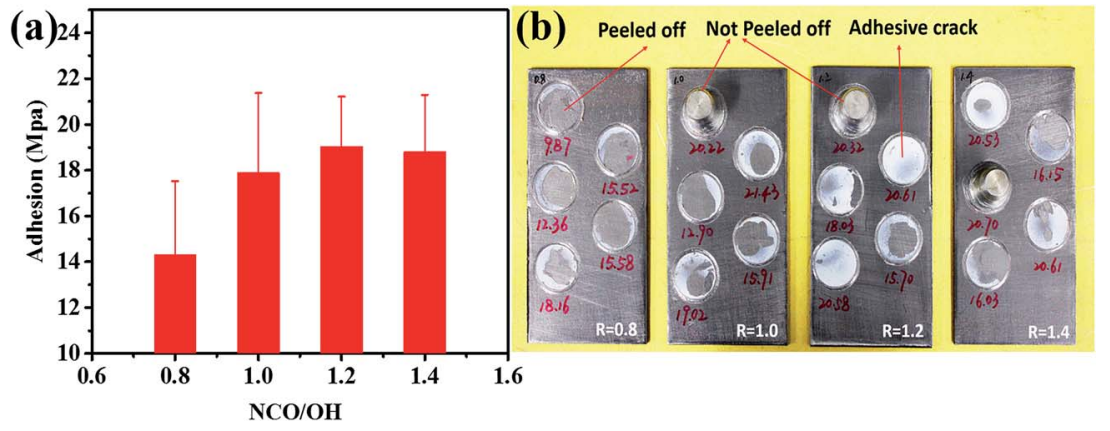

Fig. 9 (a) Pull-off adhesion results of acrylic polyurethane coatings (b) specific areas of pull-off adhesion measurement. 
strength is usually larger than that of the test value. Fig. 9(b) the adhesion strength is getting high with that of $\mathrm{NCO} / \mathrm{OH}$ ratios. Therefore, raising the $\mathrm{NCO} / \mathrm{OH}$ ratios is helpful to enhance adhesion strength, which resulted from interaction force between urethane and urea of the coatings with hydrogen atoms of the substrate.

\section{Conclusions}

Acrylic polyurethane coatings with different $\mathrm{NCO} / \mathrm{OH}$ ratios were prepared and characterized. Coating degradation was test in $3.5 \mathrm{wt} \% \mathrm{NaCl}$ solution and the EIS measurement results revealed that the coating with $\mathrm{NCO} / \mathrm{OH}=1.4$ could protect the mild steel from corrosion effectively, which is attributed to formation a dense three-dimensional structure under the condition of excess curing agents exists. We can see from the morphology of the surface that, the coating with $\mathrm{NCO} / \mathrm{OH}=1.2$ or $\mathrm{NCO} / \mathrm{OH}=1.4$ still possessed good scratch resistance and hydrolysis resistance after 50 days immersion, which contributes to prolonging the life of coating drastically. Acrylic polyurethane coatings with high $\mathrm{NCO} / \mathrm{OH}$ ratios have more urethane groups than coatings with the low $\mathrm{NCO} / \mathrm{OH}$ ratios measured by ATR-FTIR, resulting in better water resistance and adhesion strength. Most of the paint distributors do not give advice or only recommend the ratio of curing agent to resin is 1.0-1.05. However, through experiments, we found that coatings with more proportion of urethane linkage have better mechanical properties and corrosion resistance. Thus, it is meaningful to improve the $\mathrm{NCO} / \mathrm{OH}$ ratios in a certain range under the consideration of excellent protection performance.

\section{Acknowledgements}

This work was supported by National High Technology Research and Development Program (2012AA03A611), the Public Science and Technology Research Funds Projects of Ocean (no. 201405013-5), National Natural Science Foundation of China (20836006).

\section{References}

1 H. W. Engels, H. G. Pirkl, R. Albers, R. W. Albach, J. Krause, A. Hoffmann, H. Casselmann and J. Dormish, Angew. Chem., Int. Ed., 2013, 52, 9422-9441.

2 D. K. Chattopadhyay and K. V. S. N. Raju, Prog. Polym. Sci., 2007, 32, 352-418.

3 C. W. Phetphaisit, J. Namahoot, K. Saengkiettiyut, J. Ruamcharoen and P. Ruamcharoen, Prog. Org. Coat., 2015, 86, 181-189.

4 S. M. Mirabedini, M. Sabzi, J. Zohuriaan-Mehr, M. Atai and M. Behzadnasab, Appl. Surf. Sci., 2011, 257, 4196-4203.

5 J. H. Li, R. Y. Hong, M. Y. Li, H. Z. Li, Y. Zheng and J. Ding, Prog. Org. Coat., 2009, 64, 504-509.
6 V. V. Gite, P. P. Mahulikar and D. G. Hundiwale, Prog. Org. Coat., 2010, 68, 307-312.

7 M. Song and D. Cai, In Situ Synthesis of Polymer Nanocomposites, 2011, pp. 169-220.

8 G. Wang, K. Li, W. Zou, A. Hu, C. Hu, Y. Zhu, C. Chen, G. Guo, A. Yang, R. Drumright and J. Argyropoulos, Prog. Org. Coat., 2015, 78, 225-233.

9 Y. Zhu, J. Xiong, Y. Tang and Y. Zuo, Prog. Org. Coat., 2010, 69, 7-11.

10 C. H. Hare, J. Prot. Coat. Linings, 2000, 17, 34-44.

11 C. Jin, J. Lu, W. S. Li, L. Zhou, Q. M. Huang and X. H. Yang, J. Appl. Polym. Sci., 2006, 102, 4958-4962.

12 M. Melchiors, M. Sonntag, C. Kobusch and E. Jürgens, Prog. Org. Coat., 2000, 40, 99-109.

13 W. Nierzwicki, J. Appl. Polym. Sci., 1985, 30, 761-768.

14 V. Lavaert, M. Moors and E. Wettinck, J. Appl. Electrochem., 2002, 32, 853-857.

15 H. C. Yu, B. Z. Chen, X. C. Shi, H. Y. Wu and B. Li, J. Appl. Electrochem., 2008, 39, 303-309.

16 F. Mansfeld, J. Appl. Electrochem., 1995, 25, 187-202.

17 N. Buenfeld and J.-Z. Zhang, J. Mater. Sci., 2000, 35, 39-44.

18 D. Chu, J. Wang, Y. Han, Q. Ma and Z. Wang, RSC Adv., 2015, 5, 11378-11384.

19 N. Coniglio, K. Nguyen, R. Kurji and E. Gamboa, Prog. Org. Coat., 2013, 76, 1168-1177.

20 Q.-A. Huang, R. Hui, B. Wang and J. Zhang, Electrochim. Acta, 2007, 52, 8144-8164.

21 M. Moradi, H. Yeganeh and S. Pazokifard, RSC Adv., 2016, 6, 28089-28102.

22 M. Nematollahi, M. Heidarian, M. Peikari, S. Kassiriha, N. Arianpouya and M. Esmaeilpour, Corros. Sci., 2010, 52, 1809-1817.

23 Y. González-García, S. González and R. M. Souto, Corros. Sci., 2007, 49, 3514-3526.

24 C. Lee and F. Mansfeld, Corros. Sci., 1998, 41, 439-461.

25 J. R. Scully, J. Electrochem. Soc., 1989, 136, 979-990.

26 E. Akbarinezhad, M. Ebrahimi and H. R. Faridi, Prog. Org. Coat., 2009, 64, 361-364.

27 I. C. Margarit and O. R. Mattos, Electrochim. Acta, 1998, 44, 363-371.

28 A. Magalhães, I. Margarit and O. Mattos, Electrochim. Acta, 1999, 44, 4281-4287.

29 F. Chen and P. Liu, ACS Appl. Mater. Interfaces, 2011, 3, 26942702.

30 X. Guo, K. Du, Y. Wang, Y. Shao and F. Wang, Surf. Coat. Technol., 2012, 206, 4833-4839.

31 H. Wei, D. Ding, S. Wei and Z. Guo, J. Mater. Chem. A, 2013, 1, 10805.

32 G. Walter, Corros. Sci., 1991, 32, 1041-1058.

33 A. K. Mishra, D. K. Chattopadhyay, B. Sreedhar and K. V. S. N. Raju, Prog. Org. Coat., 2006, 55, 231-243.

34 D. Varnell, J. Runt and M. Coleman, Macromolecules, 1981, 14, 1350-1356. 